\title{
Research on Demographic Dividend, Lewis Turning Point, Saving and Economic Growth
}

\author{
Qiong Han, Ph.D. \\ School of Economics \\ Central University of Finance and Economics \\ Beijing, China. \\ Lecturer, Yunnan College of Business Management
}

\begin{abstract}
Population has become the main factor restricting economic development in recent years. As the working-age population of China declined for the first time in 2012 and the aging population continued to increase, the influence of demographic factor on the economy is becoming greater and greater. It is widely believed in academia that the Lewis turning point has come and China's economic development is facing a huge bottleneck. The universal two-child policy has been implemented since January 1, 2016, to increase the population and stimulate economic growth. However, even if the two-child policy is implemented, the downward trend of China's labor force population still cannot be effectively curbed based on the number of 17 million newborns per year. Therefore, population can no longer be an effective driving force for economic development. It is found that the birth rates continue to fall, and an aging population is a global problem through research on population and economic development of developed countries in the world. In such an international background, use for reference of the experience of the early into the ageing country. It is unlikely to rely on increasing labor supply to promote economic development under the situation that labor population declines, with falling birth rates, and growing elderly population, and China needs to seek new economic growth mode. It is found that the increase in labor productivity, the facilitation of the labor migration, the increase of savings and the strengthening of capital deepening have become the new driving force of economic development in the future through the comparative analysis.
\end{abstract}

Keywords: demographic dividend; Lewis turning point; saving; capital deepening; economic growth

I. Current Situation of China's Economic Development

After the reform and opening up, China's economic development is a miracle in the history of human economy. We have achieved an average annual growth rate of $9.6 \%$ in the past 38 years, which is unprecedented in the history of mankind. In recent years, there is an obvious slow growth trend in China's economy, and China's economic growth rate is $6.7 \%$ in 2016. It is still very high in the world, but a $6.7 \%$ of growth rate is the lowest growth rate since 1990. Especially since the reform and opening up, for the first time economic growth declines in six consecutive years, which means that China's economy has entered a period of slow growth.

In 1978, China's GDP was 364.522 billion yuan, with a population of 962.59 million and a per capita GDP of 381.23 yuan. In 2013, China's GDP was 56884.521 billion yuan, the national population was 1360.72 million, and the per capita GDP was 41907.59 yuan.

China's GDP in 2013 was 156 times that of 1978, with an average annual growth rate of about $16 \%$ over the past 35 years. The national population was 1.41 times that of 1978, with an average annual increase of about 1 percent over the past 35 years. Per capita GDP was 110 times that of 1978, with an average annual growth rate of about 14.7 percent over the past 35 years.

If the price increase from 1979 to 2013 is taken into account, according to the data released by the National Bureau of Statistics, the CPI in 2013 was 5.948 times that of 1978. Then, China's real GDP in 2013 was 9563.638 billion yuan, 26.2 times that of 1978. In 2013, the real per capita GDP was 7,045.66 yuan, which was18.48 times that of 1978, and the average annual growth rate was about $9 \%$ in the past 35 years.

Based on the researcher's estimation on the growth rate of China's potential GDP from 1978 to 2009 and the prediction of the scenario from 2010 to 2020, a relatively similar result is obtained. For example, Kuijs L (2009) estimated that the average potential GDP growth rate of China from 1978 to 1994 was $9.9 \%$ and from 1995 to 2009 was $9.6 \%$; the average was $8.4 \%$ from 2010 to 2015 and from 2016 to 2020 was $7.0 \%$. 
Lu Yang (2012) estimated that China's growth rate of average potential GDP would drop to $7.2 \%$ based on $10.4 \%$ of 1978 to 1994 and $9.8 \%$ of 1995 to 2009 during the 12th five-year plan period and $6.1 \%$ during the 13th five-year plan period.

Table 1: the changes of GDP growth

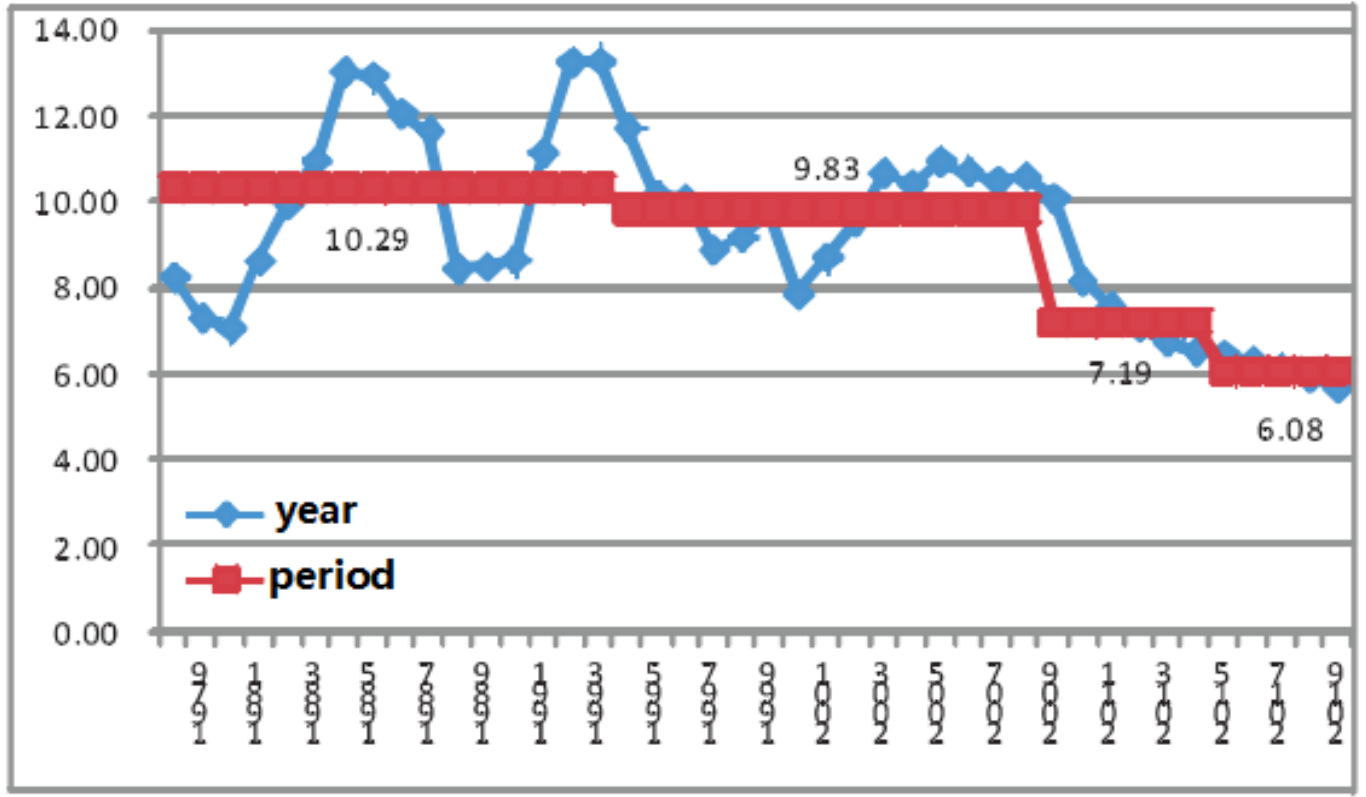

TABLE 1 Potential growth rate over time and year

Source: Lu Yang (2012) <China's potential output growth rate and its forecast>, In Cai Fang, Editor-in-Chief, <China Population and Labor Issues Report No. 13 Demographic Transition and China's Economic Rebalancing>

According to the economic operation in recent years, it further confirms the estimation and prediction of scholars that China's economy has entered a period of slow growth. There are many reasons for this phenomenon. This paper analyzes and discusses the demographic factors, Lewis turning point, savings and capital deepening, so as to put forward some feasible suggestions and opinions.

I. Demographic factors (demographic dividend, dependency ratio, labor force transfer)

(1) Demographic dividend

The demographic dividend is mainly affected by the low fertility rate and the aging population. The higher proportion of the labor force and the lower dependency rate respectively appeared an inflection point in 2010 and 2011, which indicated that China's demographic dividend is gradually disappearing. There are two main reasons for the low fertility rate. One is the decline in the birth rate caused by the "family planning" policy; the other is the obvious trend of late marriage and late childbirth, which to some extent inhibits the population growth. Cai Fang and Wang Dewen (1999) put forward that $23.71 \%$ of China's economic growth was caused by demographic dividend, while Wang Feng and Mason (2006) attributed 15\% of China's economic growth to population contribution. Although different analysis methods lead to different conclusions, to some extent, they all confirm that demographic dividend is an important factor contributing to China's economic growth miracle.

\section{Labor supply}

According to data released by the National Bureau of Statistics, China's working-age population was 907.47 million in 2016, accounting for 65.6 percent of the total population, which also means the nation's working-age population fell by 3.49 million from the previous year. This is the fifth consecutive year of net decline in China's working-age population since 2012. At present, China's labor productivity is only 1/8 of that of the developed countries in Europe and America. There is a lot of room to improve labor productivity through industrial upgrading and technological innovation. 
China's domestic labor supply fell for the first time in 2012, which has been closely linked to the country's six-year economic downturn. Looking at the international historical situation, Japan's economic downturn in the 1990s and the shortage of labor supply are in the same line.

\section{Aging population}

Coexisting with the decline of the working-age population is the continuous deepening of the aging degree. According to statistics, in 2016, there were 230.86 million people of aged 60 or above, accounting for $16.7 \%$ of the total population, an increase of 0.6 percentage points over the previous year. The number of people aged 65 and over reached 150.03 million, accounting for 10.8 percent of the total population, an increase of 0.3 percentage points over the previous year. On the one hand, the working-age population has decreased for five consecutive years; on the other hand, the elderly population has continued to increase, which means that the burden of supporting for Chinese population is getting heavier and heavier, and there will be more and more pressure on the aged supporting in the future.

In 2000 , the proportion of the elderly population in the total population reached $7 \%$, while the dependency ratio between the working population and the elderly population reached ten to one, which means China has entered an aging society. At the end of 2013, China's elderly population was 202 million, with the aging level of $14.8 \%$. It is predicted that the proportion of the elderly population in the total population and the dependency ratio between the working population and the elderly population will reach $14 \%$ and 5:1 respectively in 2025, which means China will enter a deeply aging society. Around 2040, it will reach $21 \%$ and 2:1 respectively, entering the super aging society. The aging of the population is considered an important aspect of which population has the impact on the economy. In China, with the deepening of aging, the decline of the absolute number of working-age population and the aging of age are also increasingly prominent, which is worth paying attention by all parties.

\section{Table 2: China's population (over 60 years old)}

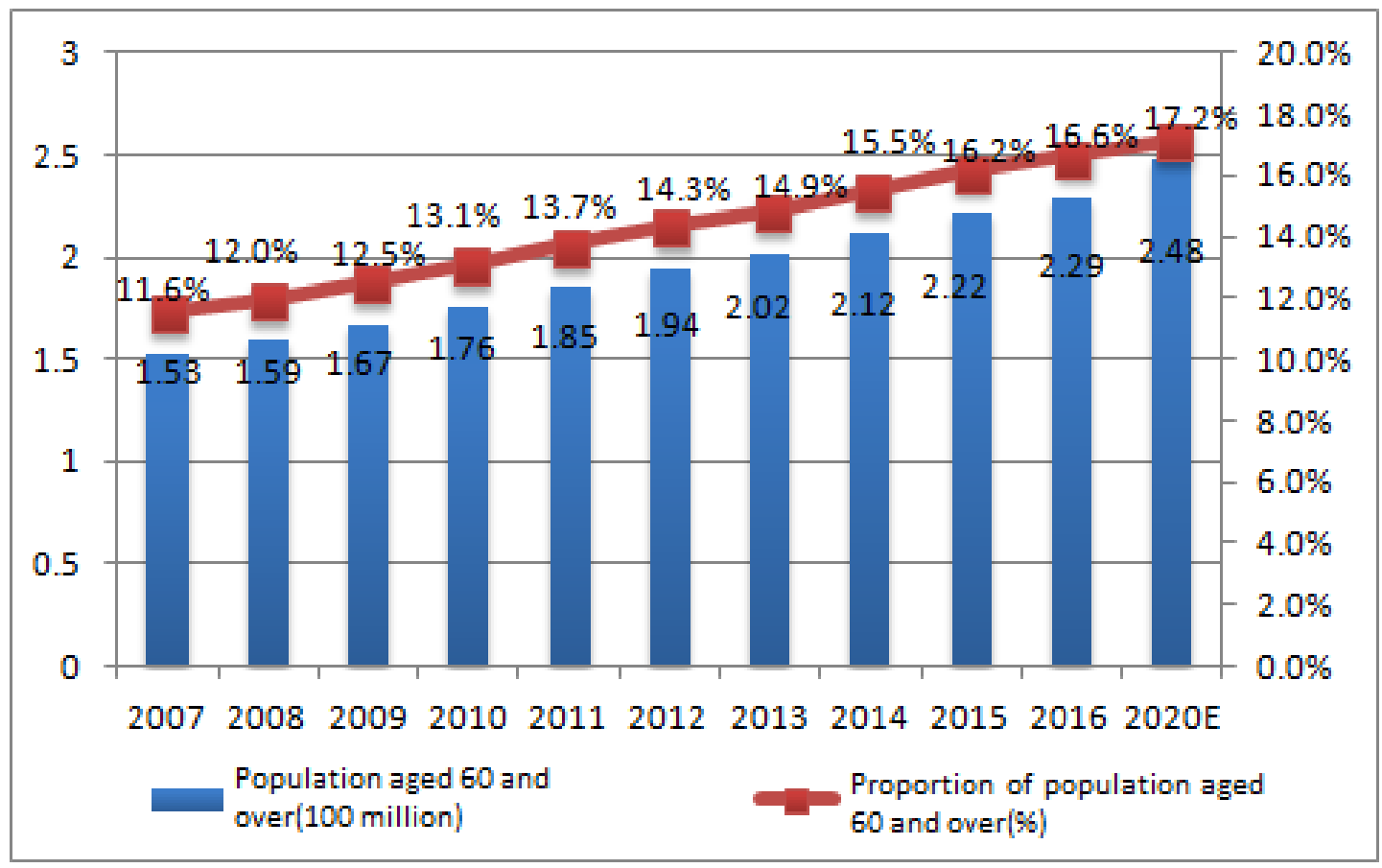

Source: Zhongjing xianlue Data Center

\section{Population dependency ratio}

From 1949 to 2012, the proportion of children from 0 to 14 years old in the total population of China changed from rising to declining. The proportion of the population aged between 15 and 64 turned from decreasing to increasing, and showed a declining trend in the past two years. The proportion of the elderly population aged 65 and above in China was basically maintained between $3.5 \%$ and $5.5 \%$ in the early stage. It began to rise from the $1990 \mathrm{~s}$ and reached $7 \%$ in 2000, marking that China has entered the stage of population aging. By the end of 2012, the proportion had climbed to $9.4 \%$. At the same time, with the change of the age structure of China's population, the population dependency ratio has also undergone profound changes. 
From 1982 to 2010, the total dependency ratio decreased from $62.6 \%$ to $34.2 \%$. In the following 2011 and 2012, the total dependency ratio was $34.4 \%$ and $34.9 \%$ respectively, indicating that the dependency burden of the whole society was increasing. Seeing from the subdivision of dependency ratio, the children's dependency ratio in China dropped sharply from $54.6 \%$ in 1982 to $22.2 \%$ in 2012 , while the old dependency ratio rose from $8.0 \%$ to $12.7 \%$. The dependency ratio is expected to be 45.4 percent in 2030 and 59.1 percent in 2050.

Table 3: Changes in China's Children's Population

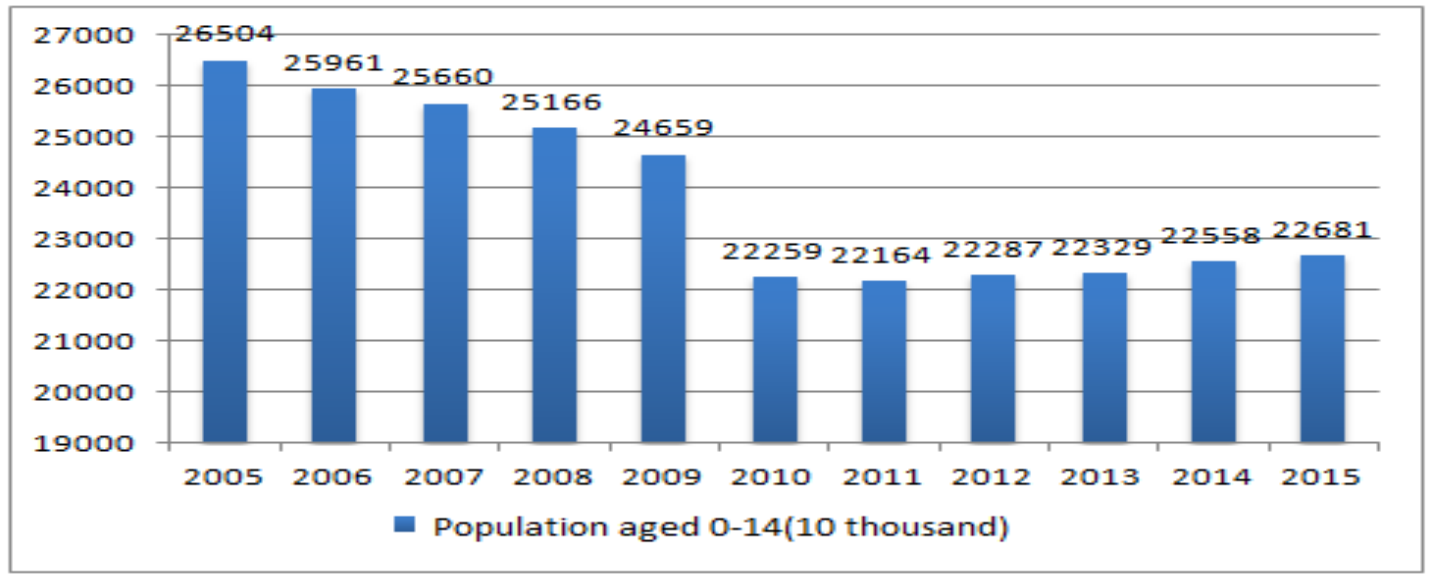

Source: Zhongjing xianlue Data Center

Table 4: Changes in China's aging population

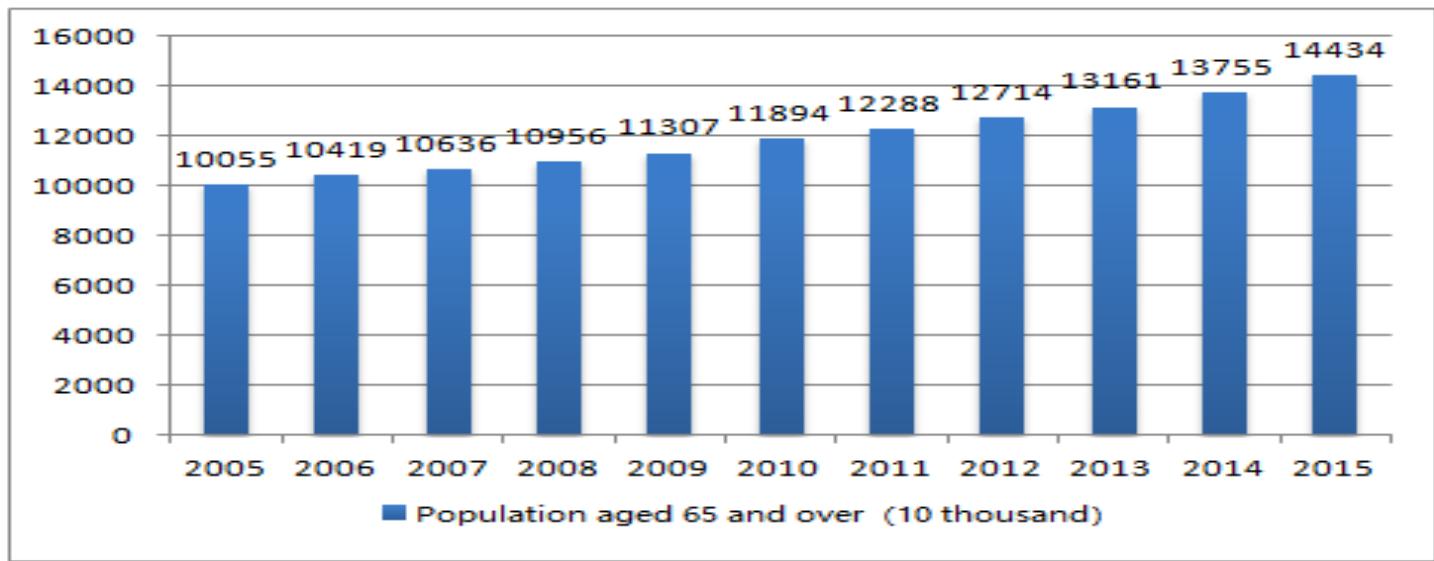

Source: Zhongjing xianlue Data Center

Table 5: China's dependency ratio

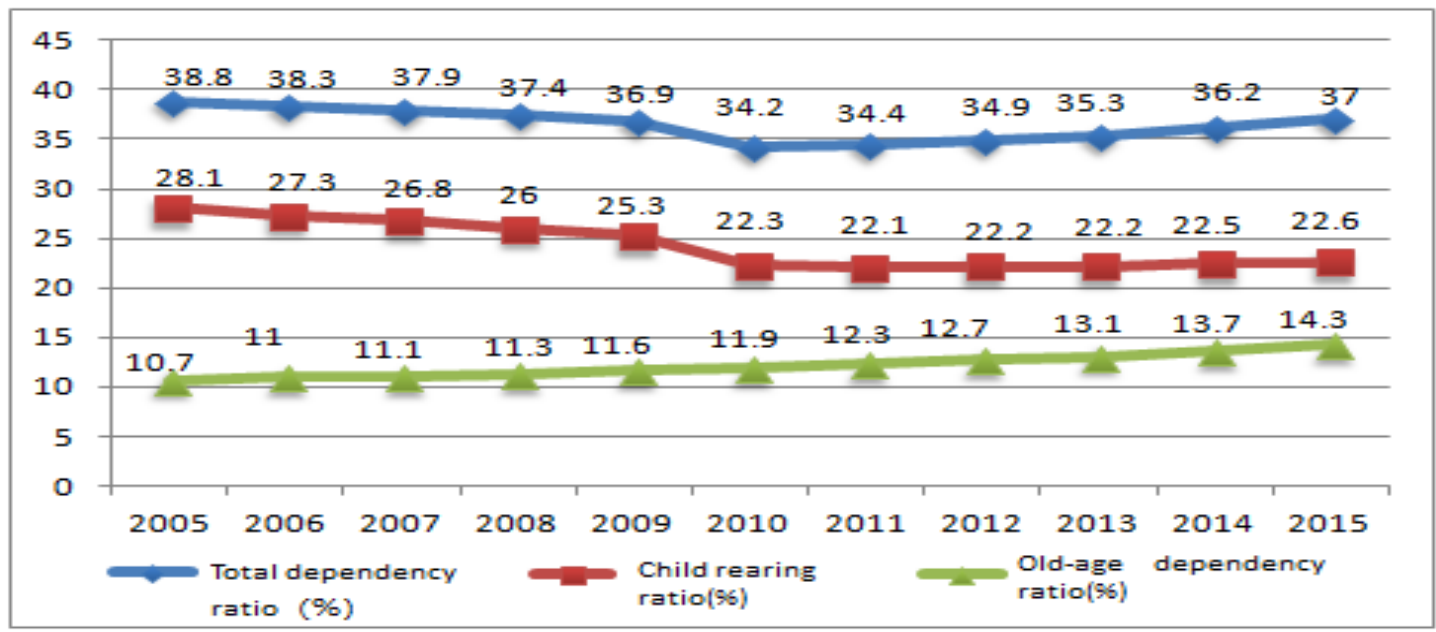

Source: Zhongjing xianlue Data Center 
Table 6: population development trends in different age groups in china

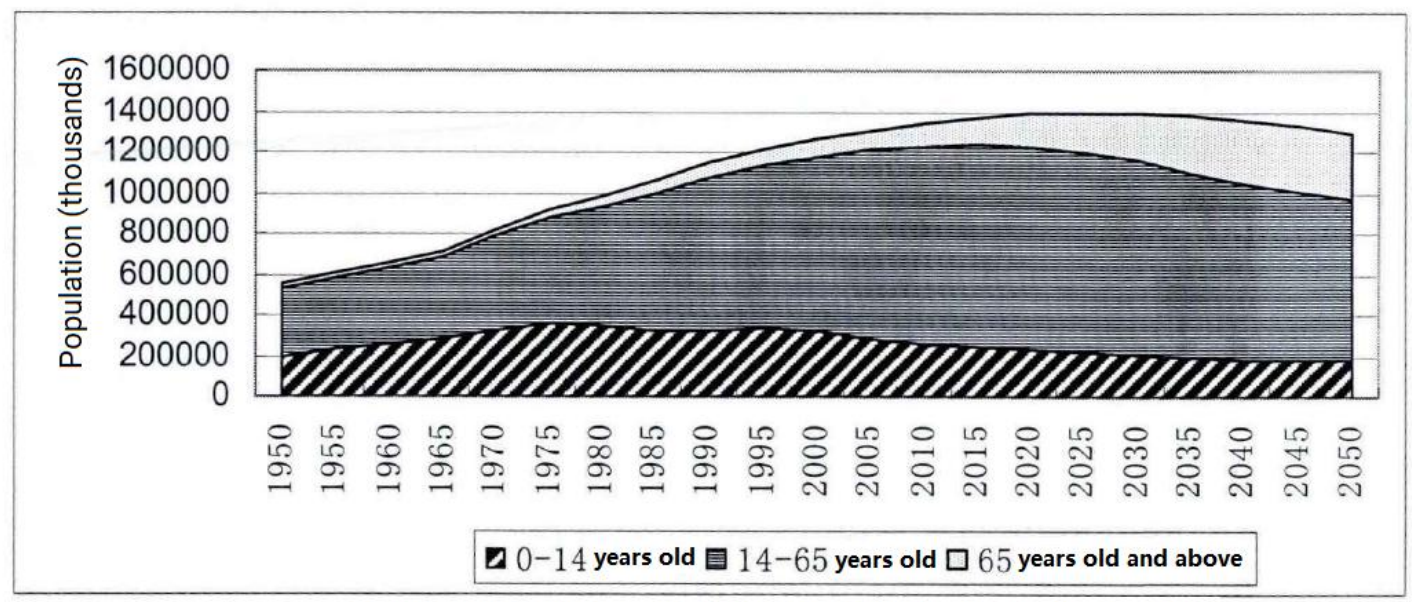

Population development trends in different age groups in China

Source: POPIN

Explaining economic growth in terms of changes in population age structure is actually a medium and long term structural perspective, which helps us understand some long-term reasons for changes in economic growth. From the perspective of "national balance sheet", the "demographic dividend" with the proportion of the working-age population and the dependency ratio as the main indicators is a necessary demographic condition for a country's rapid economic growth. However, with the advent of an aging society, a country's "population assets" are gradually transformed into "population liabilities", and the reduction of the relative or even absolute number of the working-age population will negatively restrict the growth rate of the economy through leverage such as savings rate and investment rate.

II. Lewis turning point

According to China's current development situation, although we are facing the decline of the labor force population, this does not mean the arrival of the second turning point of Lewis. Looking back at the basic mechanism of China's economic growth, we can see that it mainly benefits from two aspects: one is the labor supply effect of demographic transition, and the other is the deepening effect of capital. According to Jianfeng Yin's model in the Turning Point of Population, Lewis Turning Point and Saving/Investment Turning Point--Discussion on China's Economic Prospect, it is not difficult to find that the turning point of population corresponding to aging will bring negative impact on economic growth only under specific conditions. That is, after the second turning point of Lewis, if both the turning point of population and the turning point of investment and savings occur at the same time, it will lead to the decline of economic growth or the reduction of output per capita. At present, the hot issue in the academia and society is whether there will be a superposition of three turning points, which will have a fatal impact on economic growth.

In previous study, we can find that although China's labor turning point (the first turning point of Lewis) has come, the second turning point of Lewis is not coming, just studying from the state of labor force, which is too early to say whether the saving investment or turning point has come. It is explained that the labor supply and capital deepening also will be the main impetus to China's economic growth for some time to come.

Jianfeng Yin's model in the Turning Point of Population, Lewis Turning Point and Saving/Investment Turning Point -Discussion on China's Economic Prospect has shown that the turning point of population does not necessarily mean the arrival of the Lewis turning point. The Lewis turning point is not only dependent on the proportion of working-age population, but also related to the deepening of capital and the transfer of labor force.

III. Savings

According to the data of the IMF, China's national savings rate has been far higher than the world average since the 1970s, and the household savings rate is still on the rise. In 2005, the global average savings rate was $19.7 \%$, while China's savings rate was as high as 51\%. In December 2014, China's household savings reached 49.9 trillion yuan, with per capita savings exceeding 35,000 yuan, making China the country with the largest amount of savings in the world. 
Table 7: Changes in savings rate

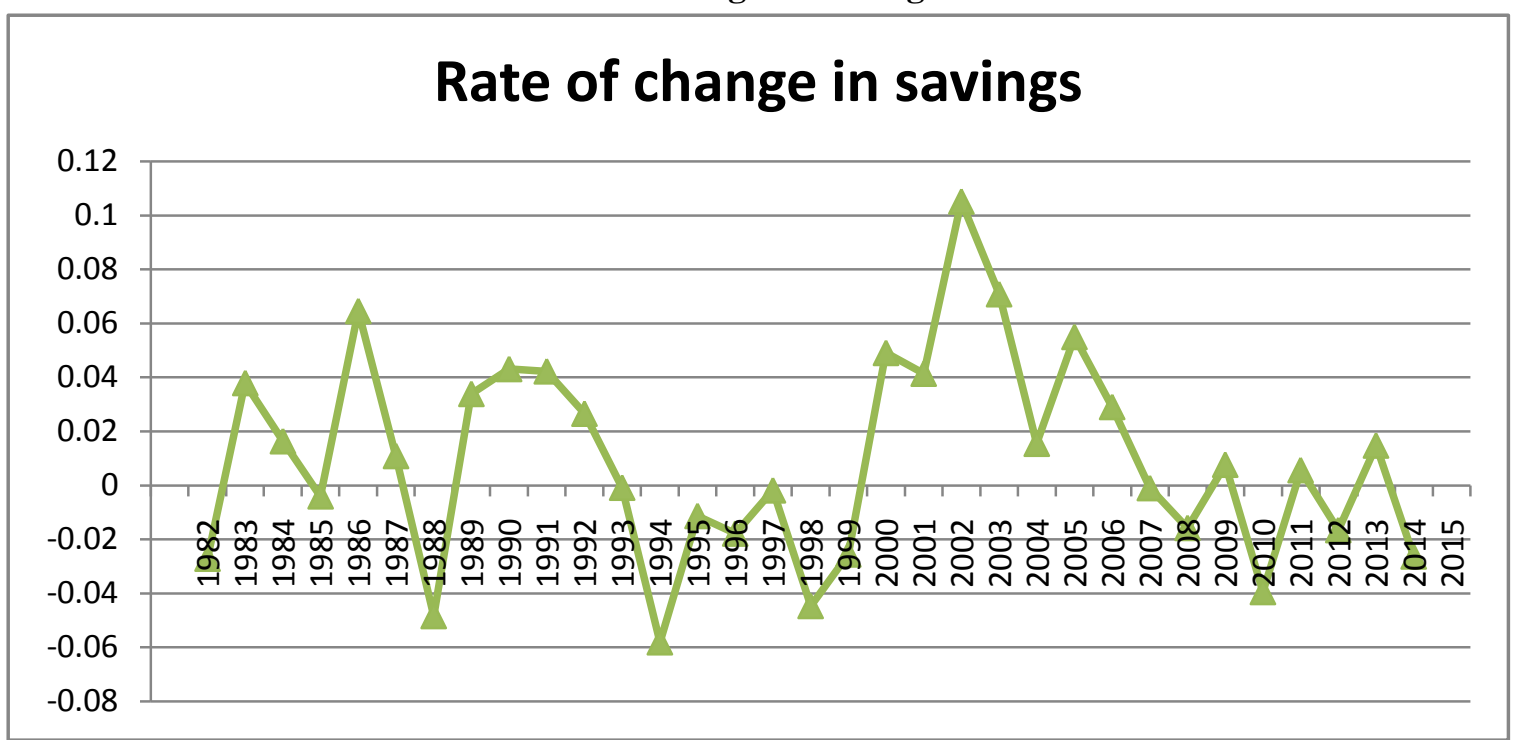

Source: World Bank Database

Table 8: total savings

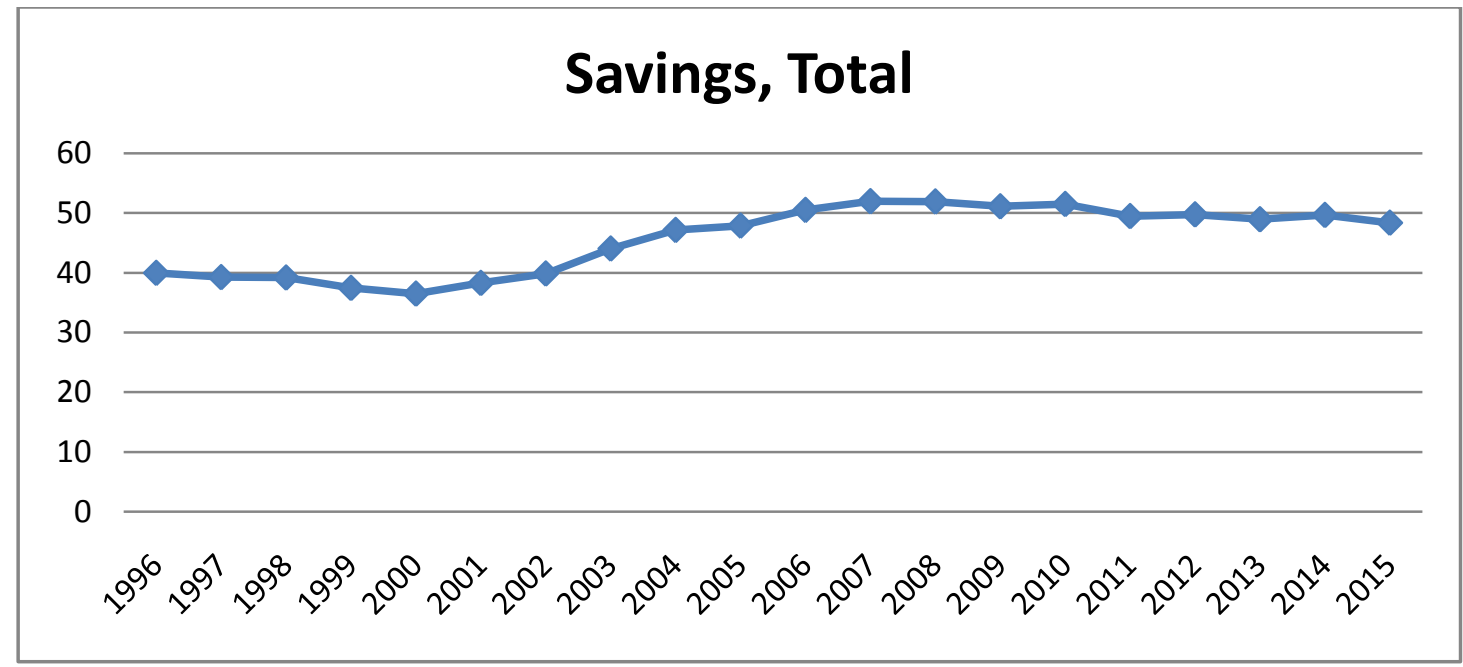

Source: World Bank Database

As can be seen from the figure, the savings rate started to rise from 2000, and the per capita GDP growth rate also showed an upward trend from 2000. When the savings rate reached a peak in 2007, the per capita GDP growth rate also reached a peak. It is clear that there is a highly positive correlation between changes in the saving rate and the growth rate of GDP per capita. (see table 12)

\section{Relationship among population, savings and economic growth}

From 1974 to 1991, the Japanese economy entered a stage of steady growth, with the economic growth rate stable at about 4.2\%, and Japan entered the stage of aging. From 1992 to 2012, Japan's economy was basically in a stagnation stage, and the statistical real GDP growth rate was only $0.22 \%$. In the same period, the proportion of the population over 65 years old reached over $20 \%$, and Japan entered a severely aging society. It can be seen that there is a significant negative correlation between the degree of aging and Japan's economic growth. This is also a problem for China's economic development to face in the future. We should learn from the choices made by Japan in this wave of aging crisis and seek advantages and avoid disadvantages, so that China's economy can make a smooth transition and maintain a relatively stable situation under the new normal.

However, in the early 1970s, Japan faced an "turning point" in both its economy and its demographic age structure. Specifically, the fourth Middle East war broke out in October 1973, followed by the oil crisis. In December 1973, the price of crude oil skyrocketed, and in February 1974, the domestic price of Japan skyrocketed. 
At the same time, Japan experienced the first negative growth after the war and Japan's post-war period of rapid economic growth came to an end. From then on, Japan entered a phase of slow and steady growth. In 1970, the proportion of the elderly aged 65 and above in the total population of Japan reached 7\%, officially entering the aging society. By 1994, the proportion of the elderly population in Japan had reached 14\%, thus entering the stage of severe aging.

Table 9: Changes in real GDP and growth rate in Japan after the war II(1995-2012)

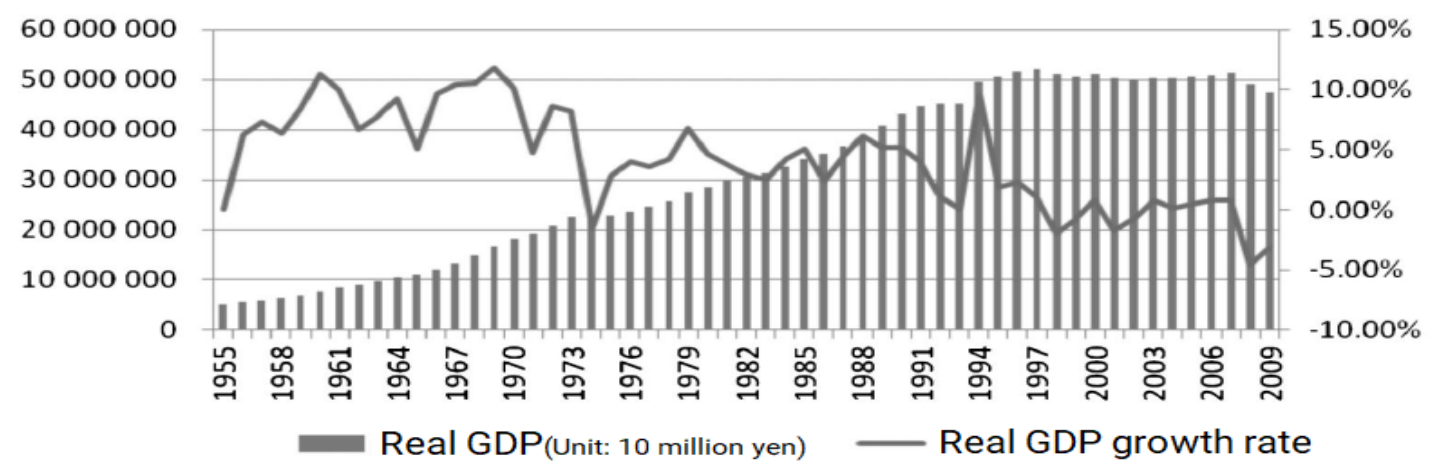

Source: Produced according to relevant data of the Statistics Bureau of the Ministry of Internal Affairs and Communications of Japan

It is worth noting that Japan's population aging process can be called "accelerated aging", and correspondingly, the period since the 1970s can also be called "accelerated aging period". Aging is a phenomenon of the world, and the reason for Japan's aging population dubbed "acceleration" as a modifier, is that the speed of aging of Japan's population is the fastest in the world's major countries, which took the least time to go from mild (ageing population accounted for $7 \%$ ) into the severe aging ( ageing population accounted for more than 14\%) (see table 10).

MULTIPLICATION YEARS OF PROPORTION OF POPULATION AGED 65 AND OVER IN MAJOR ECONOMIES OF THE WORLD

\begin{tabular}{|c|c|c|c|c|c|}
\hline \multirow[b]{2}{*}{ Country } & \multicolumn{3}{|c|}{ Proportion of population aged 65 and over } & \multicolumn{2}{|c|}{ Multiplication years } \\
\hline & $7 \%$ & $14 \%$ & $21 \%$ & $7 \% \rightarrow 14 \%$ & $14 \% \rightarrow 21 \%$ \\
\hline USA & 1942 & 2014 & 2048 & 72 & 34 \\
\hline JPN & 1970 & 1994 & 2007 & 24 & 13 \\
\hline $\mathrm{CHN}$ & 2001 & 2027 & 2038 & 26 & 11 \\
\hline GER & 1932 & 1972 & 2012 & 40 & 40 \\
\hline FRA & 1864 & 1978 & 2023 & 114 & 45 \\
\hline UK & 1929 & 1975 & 2029 & 46 & 54 \\
\hline
\end{tabular}

Source: National Social Security. Population Research Institute. Demographic Data Set http://www. ipss. go. jp/syoushika/tohkei/Popular/。

(I) Comparison of labor force

Table 11: Changes in the number of labor force in China

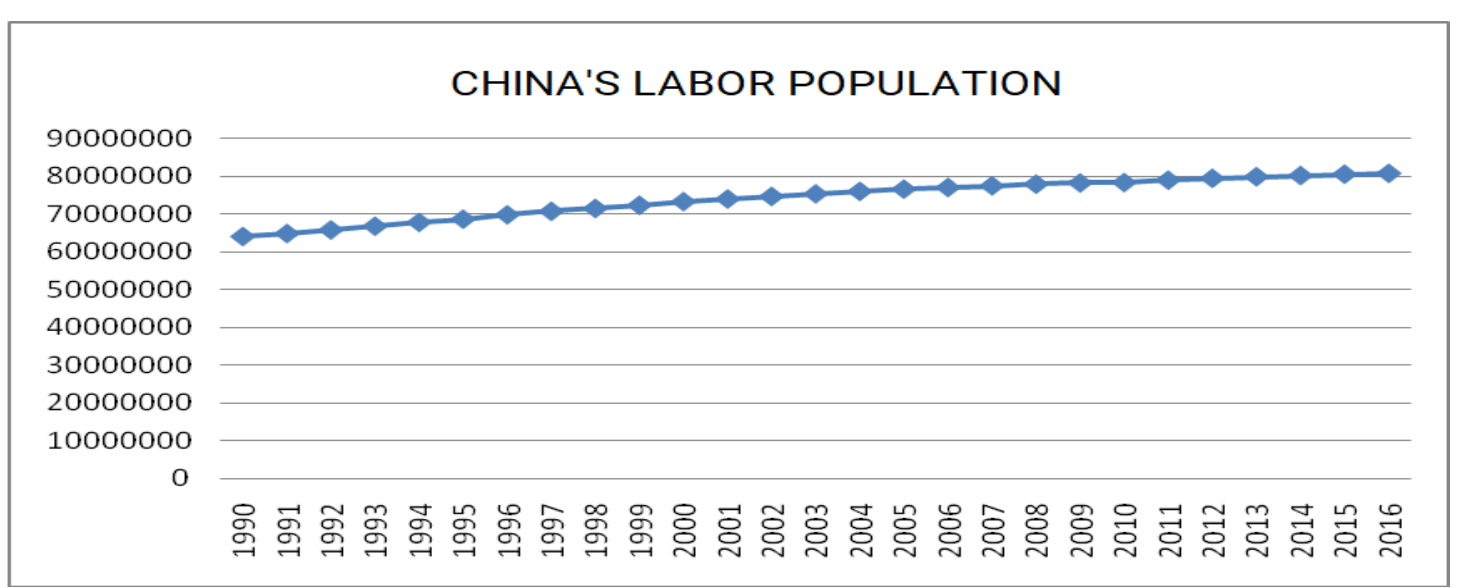

Source: World Bank Database 
Table 12: Changes in China's GDP

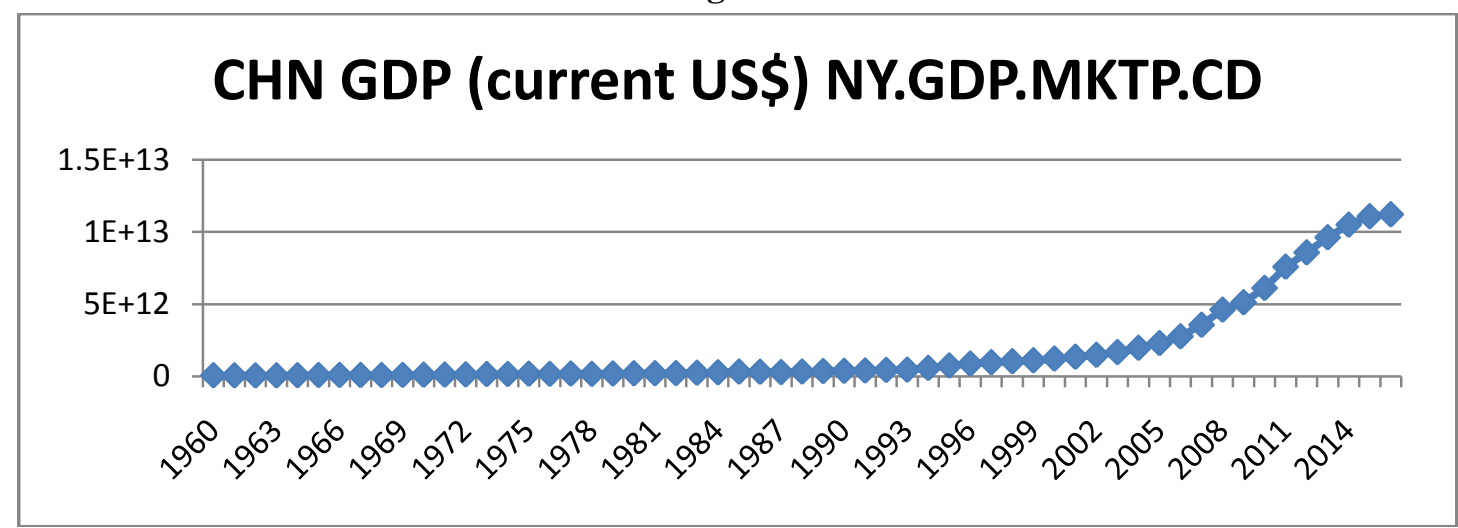

Source: World Bank Database

As is shown in the figure, around 1992, China's labor force population increased, accompanied by an increase in the total GDP. In 2012, the number of labor force began to decline, and the total GDP also showed a downward trend. It can be seen that the change of the number of labor force is highly consistent with the change of the total GDP.

Table 13: Changes in the number of working people in Japan

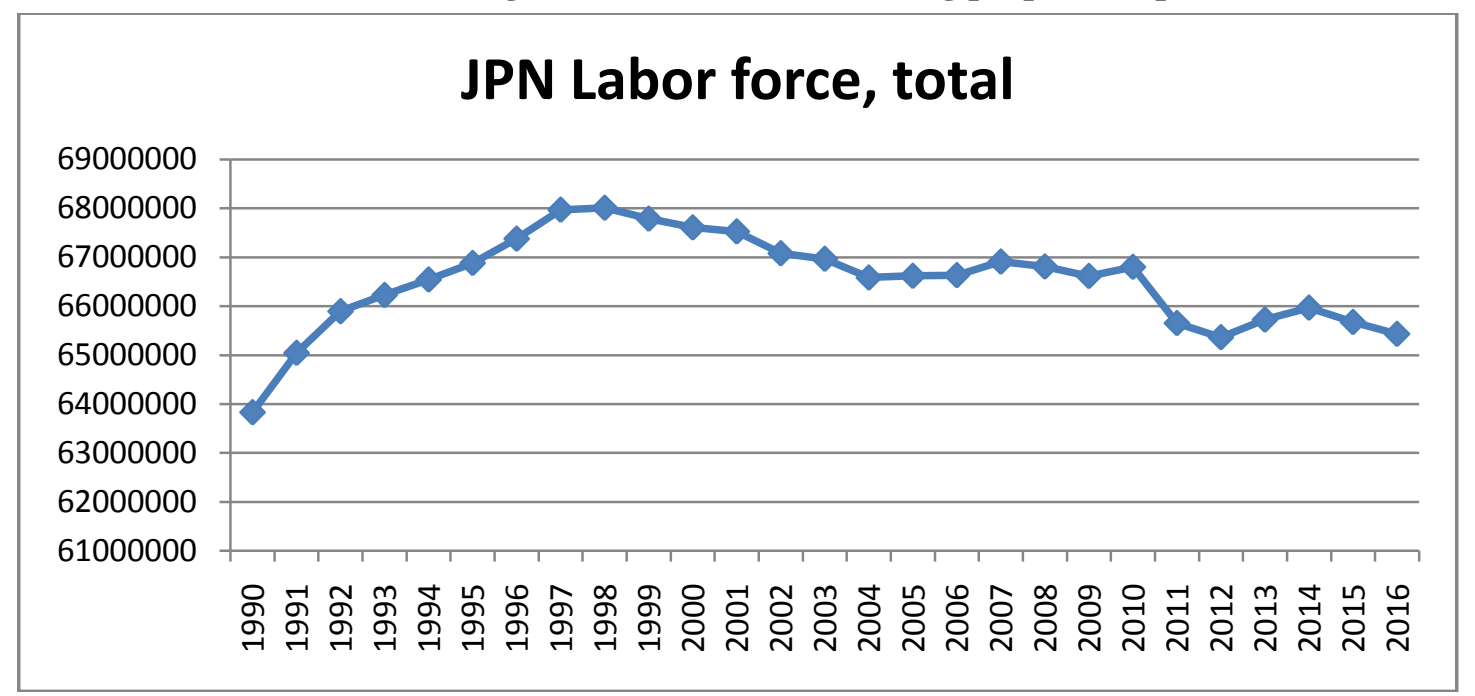

Source: World Bank Database

Table 14: Changes in the total GDP of Japan

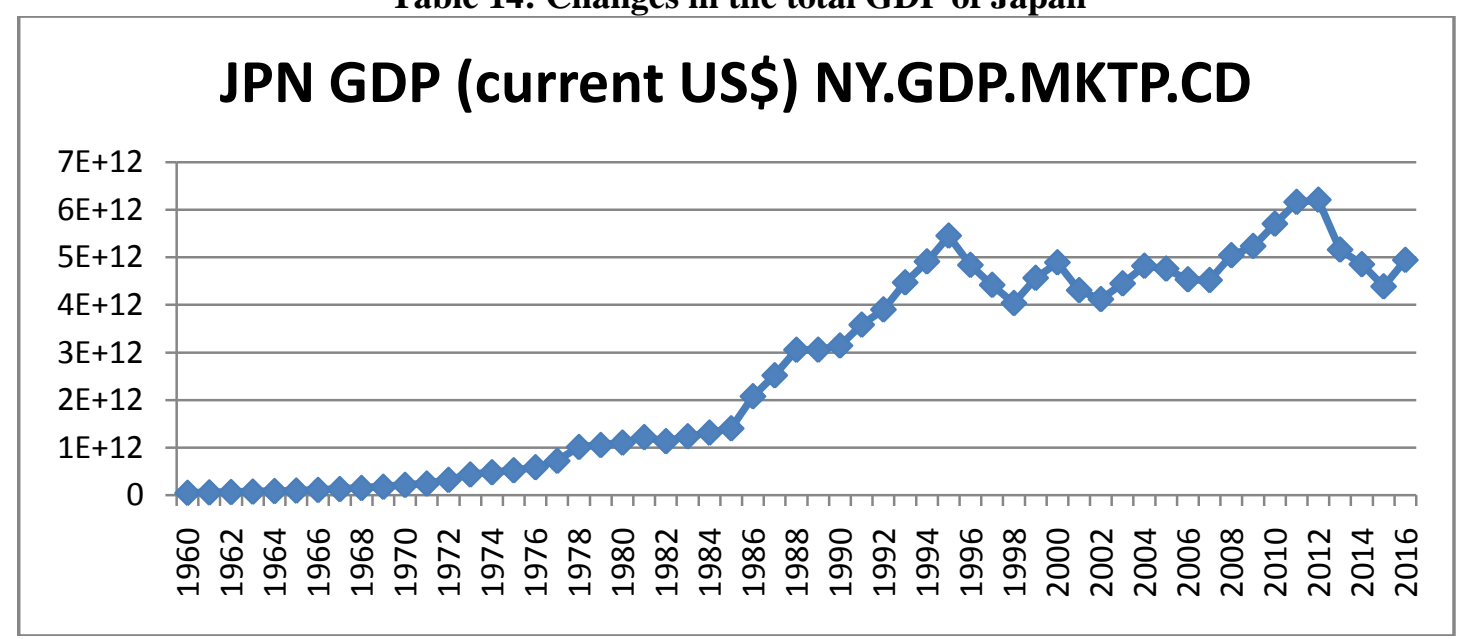

Source: World Bank Database 
Japan's GDP began to rise sharply after 1990, and we can observe that since 1990, Japan's labor force also increased significantly. Around 1996, when the number of labor force reached its height, the total GDP also reached its peak. The number of labor force in Japan maintained a high consistency with the GDP growth.

Table 15: Changes in the proportion of labor force in China and Japan

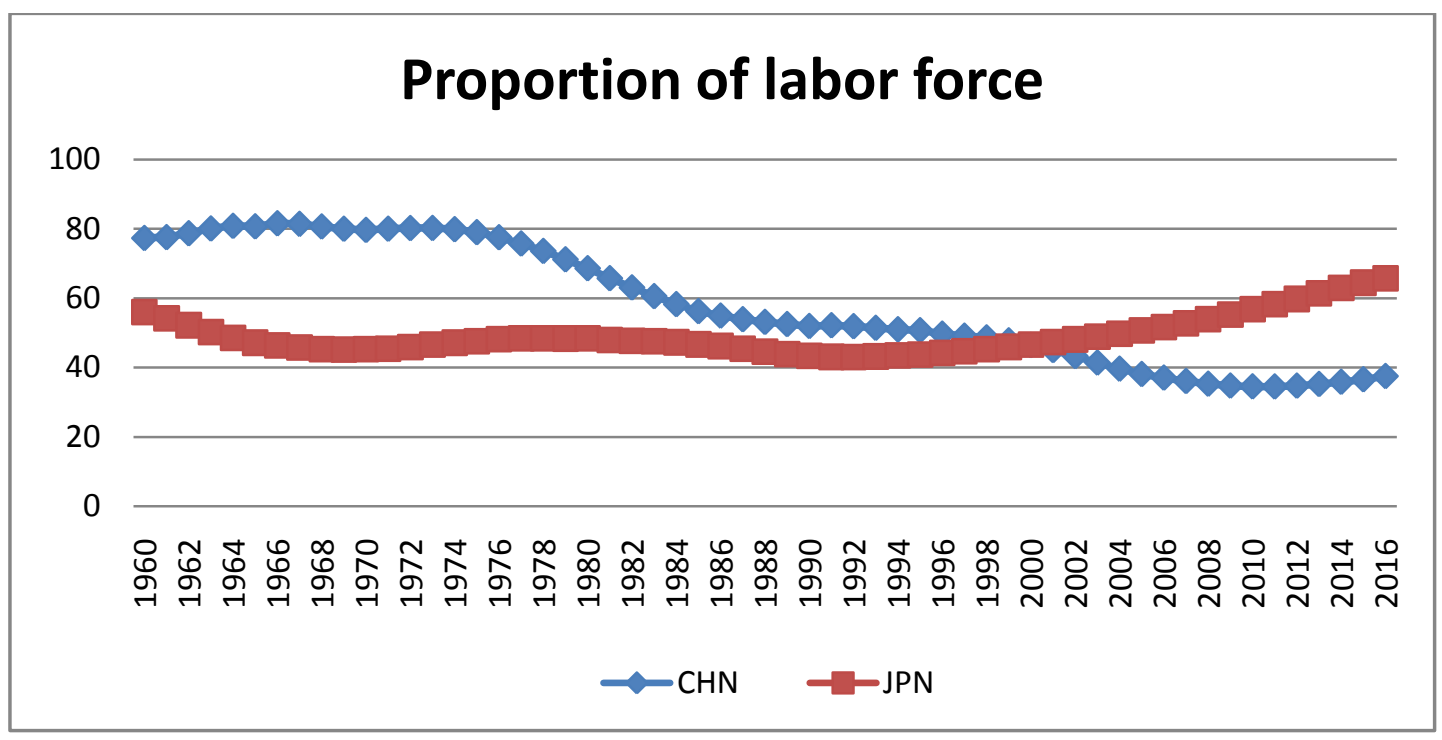

Source: World Bank Database

Table 16: Changes in the total GDP of China and Japan

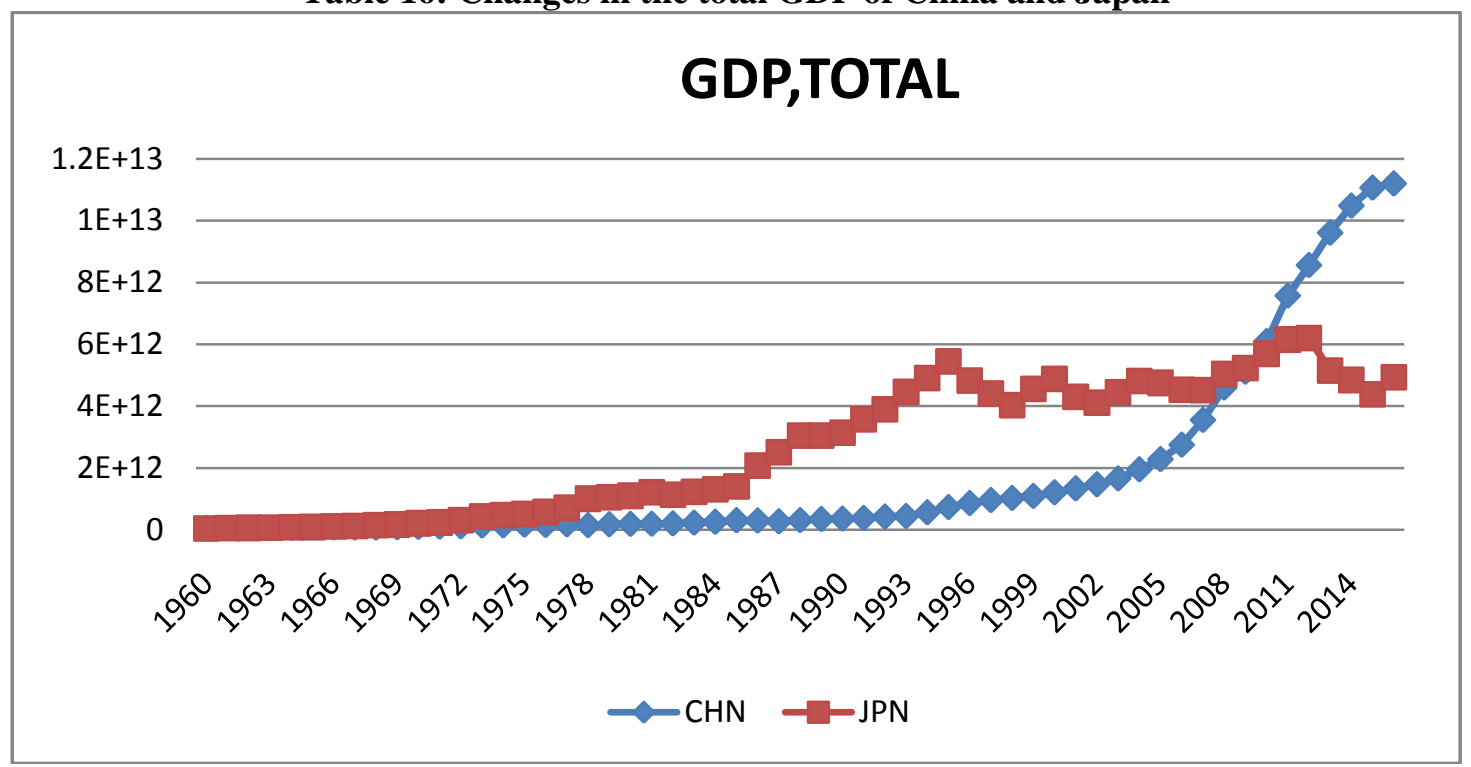

Source: World Bank Database

Labor force ratio:

China began to rise slowly in 1960, and began to decline around 1978. There was a small rise around 1990, a decline around 2000, and a slow rise again in 2010.Japan began to decline after 1960, and started to rise steadily around 1970 with a slow trend. After 1980, it declined slightly, and began to rise sharply in 1990.Difference: when the general trend of Japan declined, China rose, and it turned around about 2000. China's downward trend was obvious, while Japan's upward trend was strong.

GDP:

Since 1960, China's GDP has been in a flat trend, and it began to rise around 1992. After 2004, it increased significantly, and the growth began to slow down in 2012.Japan's GDP has been relatively stable since 1960. It began to rise slowly in 1970, and then increased after 1990. Around 2000, Japan's GDP began to decline. Difference: during the period of rapid GDP growth in Japan, China's GDP grew slowly. 
When Japan's GDP began to decline, China's GDP grew rapidly. Around 2010, China's GDP exceeded Japan. Through data analysis, it can be seen that the change of labor force population and economic growth show a striking consistency.

Table 17: Changes in per capita GDP growth rates in China and Japan

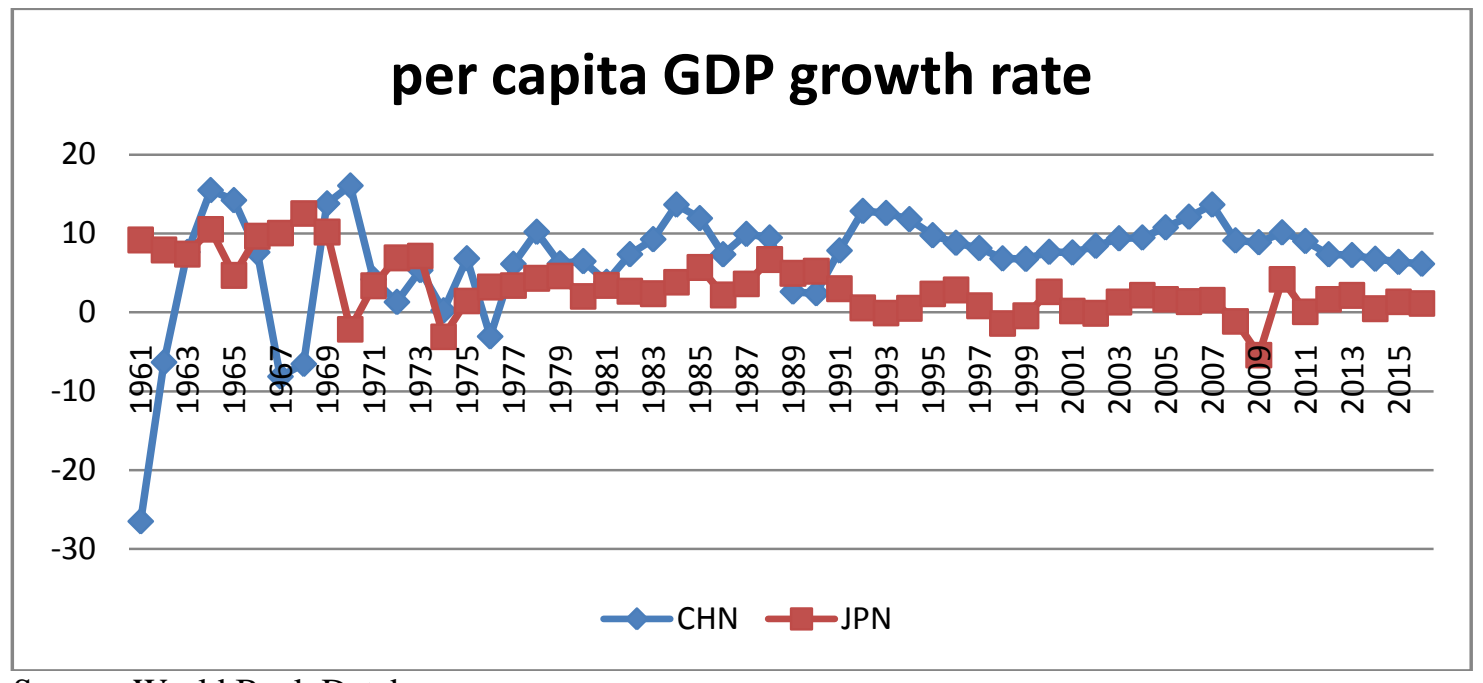

Source: World Bank Database

It can be seen from the graph, since1960, growth in GDP per capita of two countries, China and Japan has shown a pattern of almost complementary and alternating growth, which is basically consistent with the changes in labor force and savings of the two countries. In 1990 and 2000 before and after become a turning point to the growth of GDP per capita, because China is on the rise, while Japan is clearly entering a period of economic slowdown. In 2000, China's per capita GDP increased by a jump point, which corresponded to a small peak in Japan. It is not hard to see that the change in GDP per capita growth rates of the two countries is completely opposite, which depends on the change in labor force and savings of the two countries. The third turning point is that in 2010, China's GDP per capita began to decline, while Japan has a clear rise floating.

(II) Comparison of savings

Due to limited data, only data for both countries after 1996 are available. The comparison shows that after 2000, China's total savings began to increase sharply, keeping pace with China's economic growth. After 2000, Japan's savings declined, in line with its economic growth. As can be seen from the chart, China's savings are much higher than Japan's, which will become a force that cannot be ignored in our future economic development. For the continuous economic growth of China, on the one hand, we need to rely on savings to drive investment; on the other hand, we need to strengthen capital deepening, and we can also increase the ratio of labor capital to accelerate economic growth.

Table 18: Changes in total savings in China and Japan

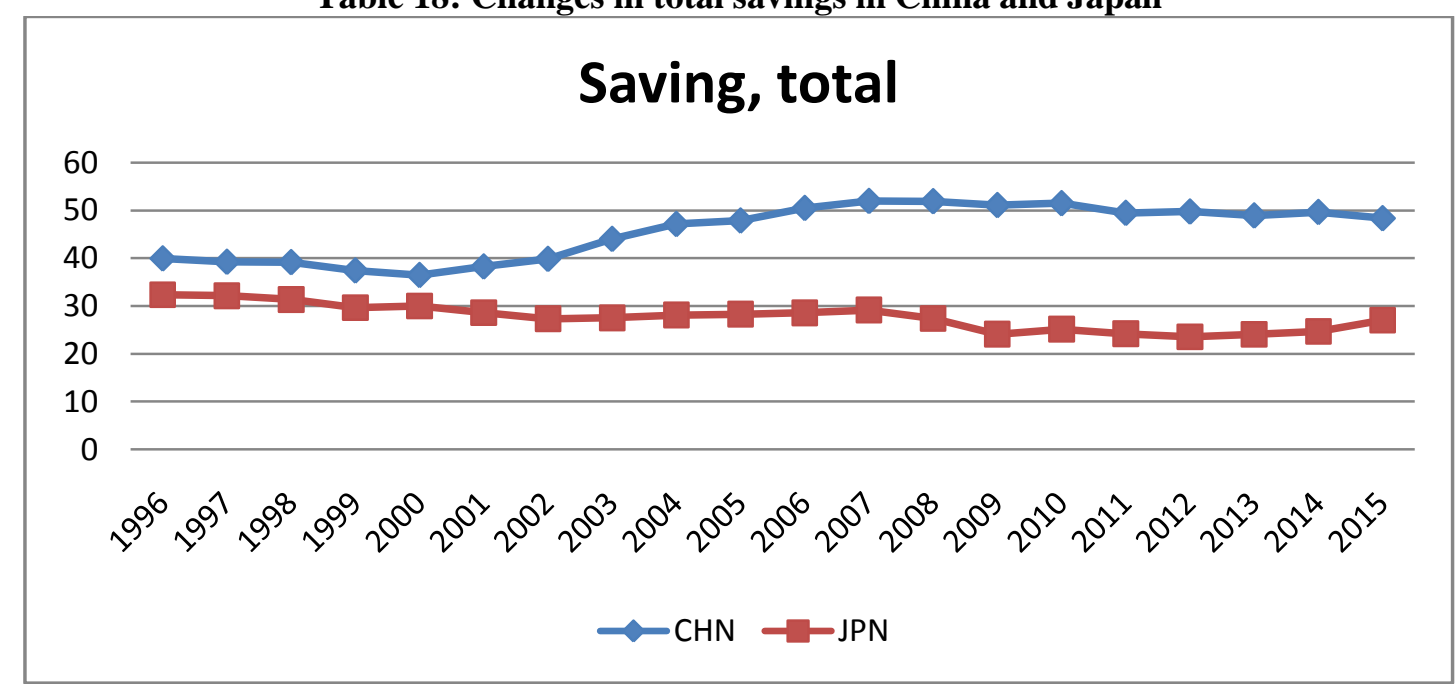

Source: World Bank Database 
Table 19: Changes in the total GDP of China and Japan

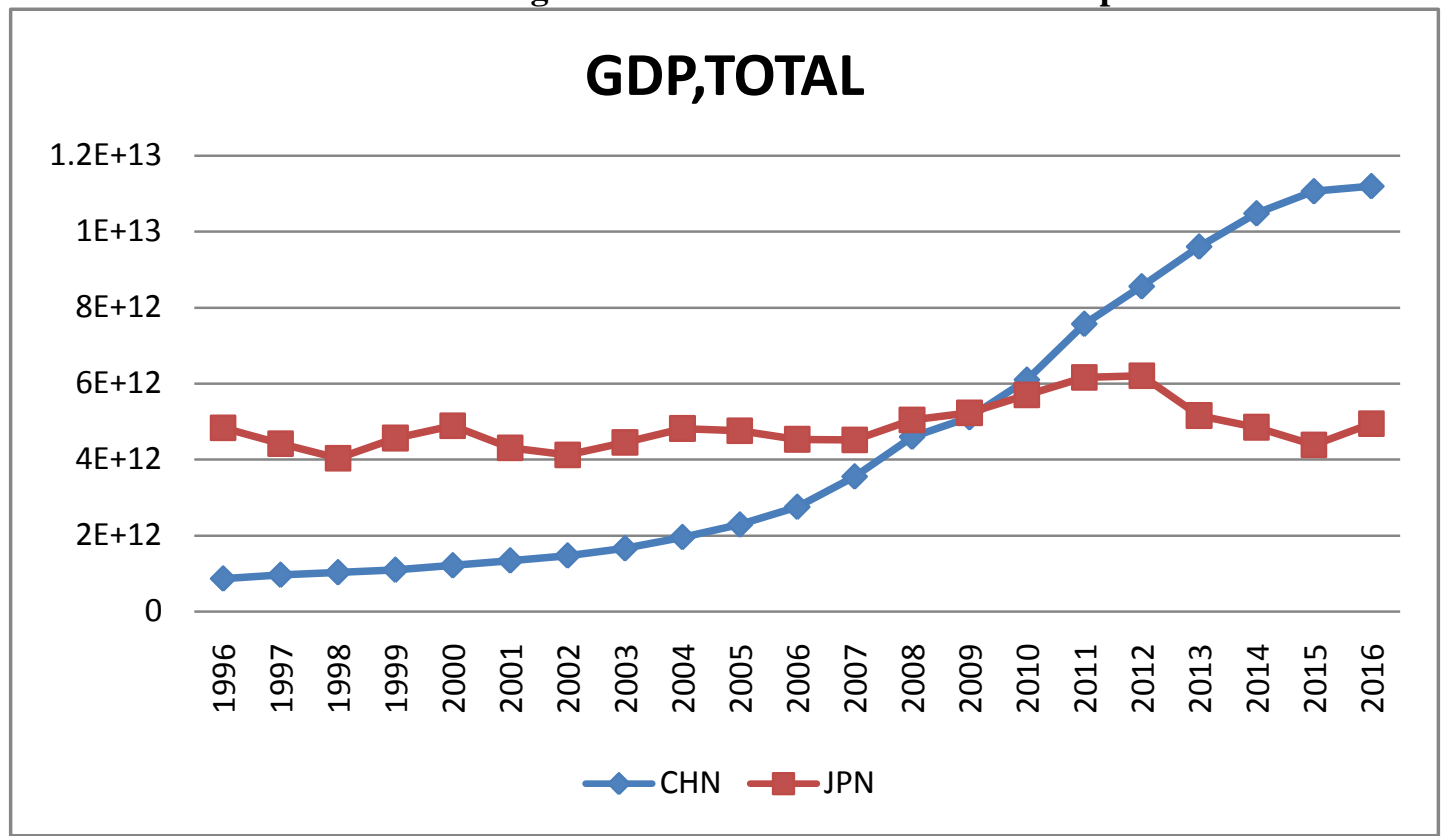

Source: World Bank Database

\section{New drivers of China's economic growth}

The advantage of China's rapid economic development stems from the high savings brought by the institutional dividend of China's reform and opening up and the demographic dividend peculiar to China, as well as the miracle of high economic growth brought about by the high investment supported by high savings, forming the "three high advantages" peculiar to China. The strength of China's economic growth has not disappeared, and the China's economy still has the potential for rapid growth. First, there is still the potential for the institutional dividend to be tapped. Second, there is still a space for the demographic dividend to shift from aggregate to structural and qualitative measures. Third, the market potential of China's economy is huge. Fourth, there is still a considerable part of savings in idle or inefficient use of resources. Therefore, our country's demographic dividend may have ended, and has appeared "Lewis turning point". Changes of demographic structure will have a direct or indirect impact on economic growth through three channels: labor supply, savings and technological progress. Studying the impact of demographic changes on household savings, we can grasp the change trend and possible impact of savings as early as possible, and provide a basis for the transformation of economic development mode.

(I) Improve the labor productivity

China's economy has experienced a peak of rapid development, attracting the attention of the world. However, after high-speed operation, it inevitably faces a bottleneck period of development, which to a great extent is because of the disappearance of the demographic dividend. However, the demographic dividend obtained from the demographic transition is one-off and not repeatable. Therefore, we should not blindly rely on the demographic dividend for economic development. We should also seek new driving forces other than the demographic dividend to promote economic development. We do not deny the fact that the economy depends on human development, but it was not developed by population. It was developed by human productivity. Economic development needs power, and this power is undoubtedly productivity. Population and productivity are not the same concept, and the relationship between them is very complicated. The original definition should be "current productivity, is equal to the total production capacity of each produce". This requires a real-time quantitative assessment of each producer's capacity, which is feasible in theory, but it is difficult to operate in practice. How do you quantify productivity? The productivity of journeyman and apprentice must be different. What is the equivalence between simple labor and complex labor? Factors, such as laborer's enthusiasm and degree of investment become the factor that restricts productivity, which can be summed up roughly as labor capacity. So we can conclude productivity to a simple formula: "productivity is equal to working-age population multiply by labor capacity". The premise of this formula is that a single working-age population has the same capacity to work, but this is not the case. In addition, in this formula, productivity is only a potential estimate, which cannot represent the real power invested in economic activities. 
Therefore, it is necessary to add the coefficient of "labor participation rate" into this formula. In addition, it is necessary to ignore the differences in labor ability of laborers and the changes in working enthusiasm and initiative of laborers. We further obtain "productivity is equal to working-age population multiply by labor force participation rate and multiply by labor capacity". In this formula, we can see that the productivity closely related to the speed of economic development is not equal to "population". A large population does not mean a large working population, which is also dependent on population structure. A large number of labor force does not mean a high labor force participation rate, and voluntary unemployment and employment rate are important influencing factors. The ability of an individual worker is also closely related to his education. The difference in education level directly affects the labor ability of the working population, and education is a process of dynamic development, and the effect of education on productivity and economic development has obvious hysteresis.

At present, the proportion of the elderly population in China's total population is about $10 \%$. If the birth rate does not increase significantly, at the current development rate, there will be about two working people to support one old person by 2030, and there will be one working person to support one old person by 2050. The United States has lost 5 million workers in the past 22 years, and yet it can feed 21 million more people, mainly because of its high labor productivity. The current per capita output value of the United States is 16.2, while the per capita output value of China is 2.3, which is equivalent to $1 / 7$ of that of the United States. In other words, if China now has one working population to support one old person, and the labor productivity increases by 7 times, which will be able to feed 7 old people by one person.

Transferring the mode of economic growth and improving labor productivity has always been the goal of China's efforts in recent years. The Eighteenth National Congress of the Communist Party of China puts forward to let the market play a decisive role in the allocation of resources. The 13th five-year plan proposes to focus on improving the quality and efficiency of economic development, that is, to realize the transformation of economic development mode from investment-driven to efficiency-driven, and improve labor productivity, which is also the fundamental way to solve the social crisis of the elderly in China.

\section{(II) Promote the transfer of labor force}

Since the early 1980s, China's rapid growth has been characterized by typical dual economic development. Surplus labor has been transferred from agriculture to non-agricultural industries on a large scale, from rural areas to cities, and from the central and western regions to the economically developed coastal areas. For China's economic growth, this process of labor force transfer contributed to the efficiency of resource reallocation. For workers and families, it expanded the labor force participation rate, and increased the per capita income of low-income groups, especially rural residents, which enabled China's economy to make use of the demographic dividend and promoted the process of industrialization. If there is a large surplus of labor in agriculture, the output value will be much lower than that of other sectors. If surplus labor in this sector is transferred to other sectors with higher productivity, the efficiency of resource allocation can be significantly improved. In fact, labor transfer not only constitutes the basis of endogenous economic growth, but also constitutes the basic mechanism of economic cyclical fluctuations. As shown in the figure, the fluctuation cycle of China's labor transfer exactly corresponds to the four economic cycles since 1976, and the elongation of China's economic cycle after entering the 21 st century is closely related to the elongation of labor transfer cycle. (Jianfeng Yin, 2006).

Table 20:

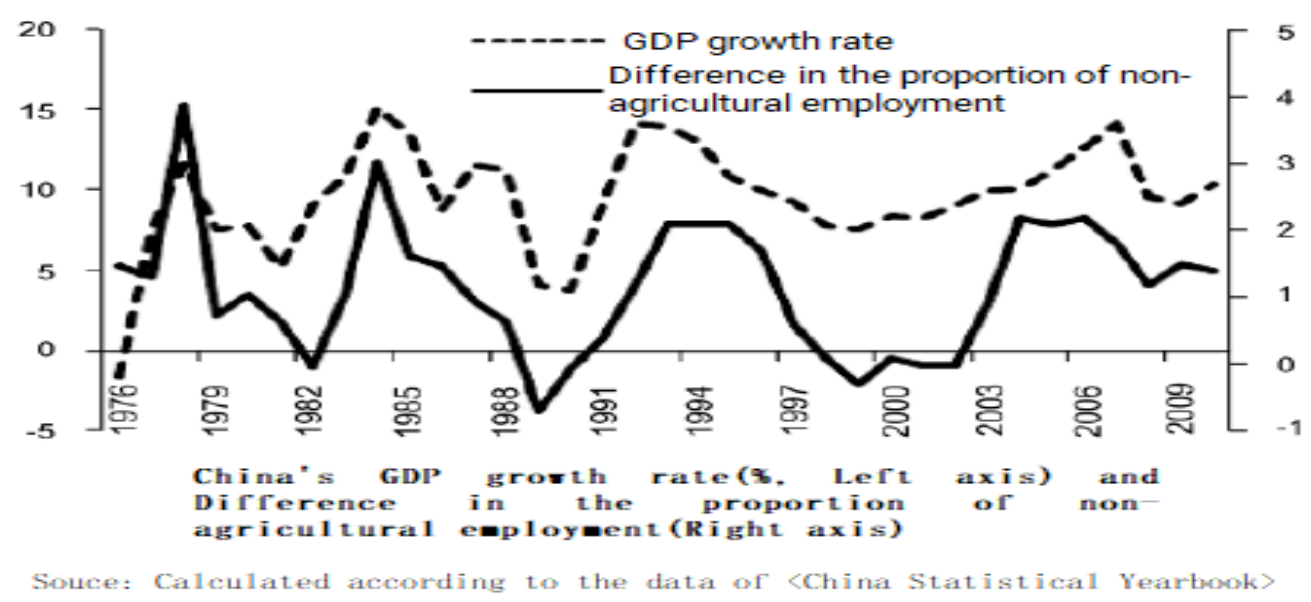




\section{(III) Increase savings}

Population is not the only factor that determines the performance of economic growth. Looking at the data of Germany and some other countries, it can be found that the turning point of savings and investment accompanied by the turning point of population is the fundamental difference between the countries where the economic crisis broke out and Germany. Dewen Wang et al. (2004) studied with Leff model and concluded that the increase of the children's dependency ratio and the old dependency ratio would reduce the savings rate, and the results were all significant. Changde Zheng (2007), Shuiying Zhong and Li Kui (2009), based on the life cycle theory, used the dynamic panel data of provincial level in China to estimate the impact of population transition and dependency burden change on the savings rate in various regions, and concluded that the decrease of the dependency ratio of children would lead to the increase of the savings rate.

1. Savings and investment drive economic growth. In the long term, the deepening of investment and capital driven by savings will be the main driving force for economic growth. On the one hand, if the dependency ratio between 0 and 14 years old decreases, the savings will increase; on the other hand, if the number of people over 65 years old increases, the consumption will increase and the savings will decrease. The increase in savings depends on a decline in children aged 0 to 14 and an increase in the proportion of those aged 65 and over. In general, children spend more than the elderly, so as long as the number of elderly people increases not to exceed the number of children who decrease, there will not be a significant decline in savings for some time to come.

2. Retirement pay and social security. Based on the current situation in China, retirees aged 65 and above enjoy retirement wages and a relatively good quality of life. Under the current medical system, the proportion of medical insurance expenditure is relatively high, and the elderly can still have part of their deposits and savings. However, as time goes by, there will be fewer and fewer old people enjoying retirement wages in the future, they will only receive the minimum living security for residents. Compared with the situation in the next economic cycle, there are still better conditions conducive to savings at present.

3. Increased average life expectancy. The average life expectancy in Japan is close to 80 years, Taiwan and Singapore around 77 years, and China is expected to reach 77 years by 2030. With the improvement of living standards, the elderly delay retirement becomes possible, while delaying retirement means that some of the money that people saved when they are young to support their spending in old age is saved, and the old people has to stay in work for a few more years. Generally speaking, the income in these years is higher than the retirement salary. So for now, postponing retirement is conducive to the increase of savings to a certain extent.

4. The current gradually improved medical system enables the elderly to save money for their old age in the absence of social security or medical insurance, which will eventually go into the savings account. Based on the above points, it is unlikely that there will be a significant decline in savings in the future, which will also become the indispensable financial power for China's economical soaring.

\section{(IV) Capital deepening}

According to Jianfeng Yin's conclusion in his thesis "the Turning Point of Population, Lewis Turning Point and Saving/Investment Turning Point -- Discussion on China's Economic Prospect", when the second turning point of Lewis comes, if the increase of labor output per capita makes up for the decline of population level turning point, the lower the capital stock per capita, or the higher the capital contribution in the production function, the more likely the capital deepening effect of capital increase per capita will exceed the labor supply effect of labor decrease. This is also a new driving force for China's economic growth in response to the disappearance of the demographic dividend and the aggravation of the aging problem. Investors and entrepreneurs should first seek to replace labor with machines as much as possible, and governments, especially those "development governments" that have more intervention in economic activities, tend to increase capital input through various investment plans and incentive policies, which will lead to a rapid rise in the capital-labor ratio. That was the case in Japan in the 1980s and 1990s, and it is a similar situation in China today. Kuijs L found that the contribution of China's capital labor ratio to labor productivity increased from $45.3 \%$ of year from 1978 to 1994 to $64.7 \%$ of year from 2005 to 2009 and is expected to increase to $65.9 \%$ from year 2010 to 2015. In fact, with the increasing role of capital input in economic growth, the improvement of labor productivity depends more and more on the deepening of capital.

\section{The factor of human capital}

Since the purpose of industrial upgrading is to improve labor productivity, and the structural transformation requires a large number of highly skilled talents, the evolution direction reflects a higher requirement for the labor's human capital, while the rate of return on education is decreasing year by year. We can observe the current status of workers' education level in different industry types, and see the minimum human capital requirements required for the reconfiguration of labor force in different industries, as well as the conversion among various industries, and the 
requirements on higher standards of education for workers have created. According to the current estimation of the workers' education level in the corresponding industries, if the workers change from labor-intensive employment in the secondary industry to capital-intensive employment in the secondary industry, the education level shall be increased by 1.3 years; while shift to technology-intensive employment in the tertiary industry, requiring 4.2 years of higher education; even a shift to labor-intensive employment in the tertiary sector would require a 0.5 year of education. The educational level required by this industrial transformation is absolutely significant, because the improvement of educational level needs long-term accumulation, rather than overnight.

According to the census and the data calculation of $1 \%$ population sample survey, even with compulsory education penetration enhancement and the enrollment expansion of higher education, the years of education for people aged over 16, during the period of 1990 to 2000 , only increased from 6.24 years to 7.56 years, and there was 1.32 years in total. In 2005, there was 7.88 years, and it has only increased by 0.32 years in five years. Although years of education cannot perfectly express the labor's human capital, it is still a quantitative indicator of human capital stock that is relatively easy to be counted, measured and obtained. If the econometric findings on the rate of return on education are translated into the phenomenon that can be directly observed in real life, we can find that low-income families are not willing to let their children to go to school continuously, especially the decline of willingness to go to high school and college, and even drop out of school at the stage of compulsory education, such as junior high school. Especially for those poor families in rural areas, the rising wage level of migrant workers has greatly increased the opportunity cost of completing compulsory education, resulting in more dropouts. According to some scholars' simulation of the workers' education level and the labor productivity of enterprises, the labor productivity will increase by $17 \%$ for every one year of workers' education. If the number of years of education of employees is converted into academic qualifications, the labor productivity of the enterprise will increase by $24 \%$ under the assumption that all employees with junior middle school education are high school graduates. If the number of years of education is further improved to all junior college graduates, the labor productivity of the enterprise can be increased by another $66 \%$.

\section{Conclusions and Summaries}

Facing the situation on the decrease of working-age population, disappearance of demographic dividend and aging exacerbation, solve these problems through raising labor productivity, industrial upgrading and structural adjustment, reducing the number of labor-intensive enterprises for labor occupation. The use of artificial intelligence and machine liberates labor force from industries with low production efficiency, and promotes the transfer of labor force from the agriculture sector to the non-agricultural sector. At the same time, improve the education level of the workers, by increasing the human capital of labor, so that finally achieve the purpose of improving labor productivity. Moreover, encourages the birth of children, and decreases the decline trend of incoming labor force, as well as to change the proportion of the aging population in the total population through the adjustment of population structure, and finally strengthens the capital deepening through the promotion of idle and inefficient use of savings, so as to provide continuous power for economic growth.

\section{References}

Kang Jianping, Ren Jian, Zhang Bo. Analysis of the Impact of Population Structure Change on China's Household Saving Rate_-Based on Lewis Inflection Point Theory [J]. Western Finance, 2016, (09): 26-31. [2017-08-29 ]. DOI: 10.16395/j.cnki.61-1462/f.2016.09.006

Lu Yang, Cai Fang. From demographic dividend to reform dividend: based on the simulation of China's potential growth rate [J]. World Economy, 2016, 39 (01): 3-23. [2017-08-29].

Wang Lei. The Impact of Demographic Change on Economic Development — A Study of Tonglu from the Perspective of Lewis Turning Point[J]. Manager, 2014, (34): 171-173. [2017-08-29].

Wang Xiaofeng, Ma Xueli. The Impact of Population Factors on the Economic Growth of Japan during the Accelerating Period of Aging__From the Perspective of Double Turning Point of Population and Economy[J]. Modern Japanese Economy, 2014, (05): 1-12. [2017- 08-29]. DOI: 10.16123/j.cnki.issn.1000355x.2014.05.002

Yang Yang. China's Demographic Transition: A Discussion on China's Demographic Dividends[J]. Dang Shibo Cai (Theory), 2014, (07): 41-42. [2017-08-29].

Liu Kaihao, Liu Yulin. The Mystery of China's Economic Growth: An Interpretation of Changes in Population Structure[J]. Economic Science, 2014, (03): 5-21. [2017-08-29].

Cai Fang, Wang Meiyan. The Reality of Income Gap in China and the Risk of Middle Income Trap[J]. Journal of Renmin University of China, 2014, 28(03): 2-7. [2017-08-29]. 
Cai Fang. How population factors affect China's future economic growth [J]. Science Development, 2013, (06): 101113. [2017-08-29].

Cai Fang. On the Slowdown of China's Economy from the Perspective of Demography[J]. China Market, 2013, (07): 12-16. [2017-08-29].

Cai Fang. Demographic Dividend and Sustainable Growth of China's Economy [J]. Gansu Social Sciences, 2013, (01): 1-4. [2017-08-29]. DOI: 10.15891/j.cnki.cn62- 1093/c.2013.01.061

Zhang Wei. Analysis of the impact of population age structure change on economic growth in China [D]. Dongbei University of Finance and Economics, 2012.

Cai Fang, Wang Meiyan. A glimpse of the current situation of human capital in China_- How to develop new sources of growth after the disappearance of demographic dividends[J]. People's Forum - Academic Frontiers, 2012, (04): 56-65+71. [2017-08 -29]. DOI: 10.16619/j.cnki.rmltxsqy.2012.04.003

Cai Fang. China's Population and Sustainable Development [J]. Chinese Academy of Sciences, 2012, 27 (03): 314-319. [2017-08-29].

Gao Jiankun. Analysis of China's Demographic Transition and Demographic Dividend [J]. Journal of Contemporary Economic Research, 2012, (04): 58-64. [2017-08-29].

Cai Fang. Some misunderstandings about China's population and related issues [J]. International Economic Review, 2010, (06): 81-94+5. [2017-08-29].

Cai Fang. Demographic transition, demographic dividend and Lewis turning point [J]. Economic Research, 2010, 45(04): 4-13. [2017-08-29].

Cai Fang, Wang Dewen. Sustainability of China's Economic Growth and Labor Contribution [J]. Economic Research, 1999(10): 62-68.

Wang Feng, Andrew Mason, Shen Ke. Population Factors in the Process of China's Economic Transformation [J]. Chinese Journal of Population Science, 2006, 2006(3): 2-18.

Yin Jianfeng. Population Turning Point, Lewis Turning Point and Savings/Investing Turning Point_—Discussion on China's Economic Prospects [J]. Financial Review, 2012(4):1-17.

Wang Dewen, Cai Wei, Zhang Xuehui. Savings Effect and Growth Effect of Population Transformation—On the Population Factors of China's Growth Sustainability [J]. Population Research, 2004, 28(5): 2-11.

Zheng Changde. Empirical Study on the Relationship between Population Structure and Savings Rate in Different Regions of China [J]. Population and Economy, 2007(6).

Zhong Shuiying, Li Kui. Research on the Impact of Labor Supporting Burden on Household Saving Rate[J]. China Population Science, 2009, 2009(1): 42-51.

Kuijs L . China through 2020 : a macroeconomic scenario[J]. 2010. 